\title{
Comparison of Uric Acid Quantity with Different Food in Human Urine by Flow Injection Chemiluminescence Analysis
}

\author{
Jiajia Wang, Xijuan Tan, and Zhenghua Song \\ Key Laboratory of Synthetic and Natural Functional Molecule, Chemistry of Ministry of Education, \\ College of Chemistry and Materials Science, Northwest University, Xi'an 710069, China \\ Correspondence should be addressed to Zhenghua Song; songzhenghua@hotmail.com
}

Received 27 July 2013; Accepted 5 September 2013

Academic Editor: Chih-Ching Huang

Copyright (C) 2013 Jiajia Wang et al. This is an open access article distributed under the Creative Commons Attribution License, which permits unrestricted use, distribution, and reproduction in any medium, provided the original work is properly cited.

\begin{abstract}
Based on the inhibitory effect of uric acid (UA) on luminol- $\mathrm{Co}^{2+}$ chemiluminescence (CL) system, a sensitive method for the determination of UA at nanomolar level by flow injection (FI) CL was proposed. The proposed method was successfully applied to real-time monitoring of UA excretion in human $24 \mathrm{~h}$ urine with different food intake, showing that meats, vegetables, and porridge intake caused differential UA excretions of 879,798 , and $742 \mathrm{mg}$, respectively. It was also found that UA concentrations in urine under the three kinds of food intake simultaneously reached maximum at $2 \mathrm{~h}$ after meals with the values of 417,318 , and $288 \mu \mathrm{g} \mathrm{mL}{ }^{-1}$, respectively. The UA concentration in human serum was also determined by this approach, and the possible mechanism of luminol$\mathrm{Co}^{2+}$-UA CL reaction was discussed in detail.
\end{abstract}

\section{Introduction}

Uric acid (2,6,8-trihydroxypurine, UA, Figure 1), the principal breakdown product of human purine metabolism, is mainly excreted by the kidney [1]. Normally, most of UA produced from the catabolism is reabsorbed into the blood circulation system and then passes through the kidney into urine. When UA in human urine or serum exceeds the normal physiological range, it may cause gout [2], kidney injury [3], metabolic syndrome [4], cardiovascular disease [5], and type II diabetes [6]. Consequently, monitoring the concentration of UA in bodily fluids is essential in diagnosis and treatment of the corresponding diseases. Many methods have been reported for the determination of UA, such as capillary electrophoresis (CE) [7], enzymatic assay (EA) [8], high-performance liquid chromatography (HPLC) $[9,10]$, differential pulse voltammetric (DPV) [11, 12], and UV-Vis spectroscopy $[13,14]$. Chemiluminescence $(\mathrm{CL})$ has also been developed for UA determination [15-17].

Luminol with $\mathrm{Co}^{2+}$ reaction is known as a classic CL system [18]. The CL mechanism of $\mathrm{Co}^{2+}$ remarkably enhancing luminol intensity has been well studied $[19,20]$, and a variety of applications with luminol- $\mathrm{Co}^{2+} \mathrm{CL}$ system in trace analysis [21, 22] have been reported. For example, it has been applied to the determination of hydrogen peroxide [23, 24], acetaminophen [25], lanthanides [26], carbaryl [27], captopril [28], vitamin $B_{12}$ [29], gibberellic acid [30], and radical scavenging potential of ascorbic acid [31]. With luminol- $\mathrm{H}_{2} \mathrm{O}_{2}-\mathrm{Co}^{2+} \mathrm{CL}$ system, the determination of UA have been reported [32], while no real-time analysis of urine UA excretion with luminol-Co ${ }^{2+} \mathrm{CL}$ system has been described so far.

Flow injection (FI) analysis combined with CL, FI-CL, which possess merits of low limit of detection (LOD), fast response time, less reagent consumption, and simple instrumentation as well as automation, has become a very useful analytical tool in different scientific fields from food safety [33-35] to environmental chemistry [36-38]. In this work, it was found that UA could obviously quench the CL intensity of luminol- $\mathrm{Co}^{2+}$ in a flow system, with the decrements in CL intensity linearly proportional to the logarithm of UA concentrations ranging from 3.0 to $500.0 \mathrm{nmol} \mathrm{L}^{-1}$, giving the LOD of $1.0 \mathrm{nmol} \mathrm{L}^{-1}(3 \sigma)$. The relative standard deviation (RSD) was $2.5 \%$ for determining $10.0 \mathrm{nmol} \mathrm{L}^{-1} \mathrm{UA}$. At a flow rate of $2.0 \mathrm{~mL} \mathrm{~min}^{-1}$, a single UA determination cycle could 


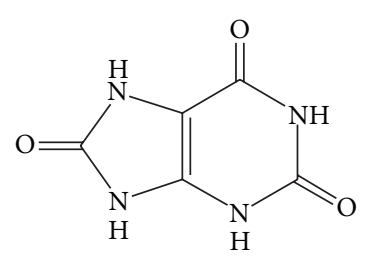

Figure 1: Chemical structure of UA.

be accomplished within $36 \mathrm{~s}$, offering a sample throughput (ST) of $100 \mathrm{~h}^{-1}$. UA excretion in urine is known to be closely associated with food intake, and the normal excretion of UA is $250-740 \mu \mathrm{g} \mathrm{mL}^{-1}$ per day [39]. Herein, quantitative monitoring of urine UA excretion with different food intake by FI-CL was proposed for the first time.

\section{Experimental}

2.1. Reagents. All chemical reagents in this work were of analytical reagent grade. Doubly deionized water purified in a Milli-Q system (Millipore, Bedford, MA, USA) with the resistivity of $18.2 \mathrm{M} \Omega \mathrm{cm}$ was used for the preparation of solutions in the whole procedure. Luminol (Fluka, Biochemika, Switzerland) and UA (Sigma) were obtained from Xian Medicine Purchasing and Supply Station, China.

The luminol stock standard solution of $2.5 \times 10^{-2} \mathrm{~mol} \mathrm{~L}^{-1}$ was prepared in $1.0 \times 10^{-1} \mathrm{~mol} \mathrm{~L}^{-1} \mathrm{NaOH}$ solution and kept in the dark. The $\mathrm{Co}^{2+}$ stock standard solution of $1.0 \times 10^{-3} \mathrm{~mol} \mathrm{~L}^{-1}$ was prepared by dissolving $11.90 \mathrm{mg}$ of $\mathrm{CoCl}_{2} \cdot 6 \mathrm{H}_{2} \mathrm{O}(99 \%)$ in $50 \mathrm{~mL}$ calibrated flask with doubly deionized water. The UA stock standard solution of $1.0 \times$ $10^{-3} \mathrm{~mol} \mathrm{~L}^{-1}$ was prepared in $1.0 \times 10^{-2} \mathrm{~mol} \mathrm{~L}^{-1} \mathrm{NaOH}$ solution and stored at $4^{\circ} \mathrm{C}$. All the daily used working standard solutions were freshly prepared from the above stock standard solutions by appropriate dilution as required.

2.2. Apparatus. The schematic profile of equipment in the flow system (Xian Remax Analysis Instrument Co. Ltd., Xi'an, China) was depicted in Figure 2. The apparatus contained a sampling system (IFFM-E), a CL detector (IFFS-A), and a recorder (a computer with IFFM-E client system). The sampling system used a peristaltic pump with four channels to pump the reagents and a six-way valve with a loop of $100 \mu \mathrm{L}$ to quantitatively inject luminol. The CL detector, which was placed inside a black box for precluding the interference from ambient light, contained a flow cell and a photomultiplier tube (PMT). The flow cell, tightly positioned on the window of PMT, was a colorless glass tube $(15 \mathrm{~cm}$ in length, $1.0 \mathrm{~mm}$ i.d.) with a spiral disk shape $(2.0 \mathrm{~cm}$ i.d.). The $\mathrm{CL}$ signal from the flow cell was directly detected by the PMT without any wavelength discrimination and the output was recorded by the computer. The polytetrafluoroethylene (PTFE) tubing $(1.0 \mathrm{~mm}$ i.d.) was used to deliver the reagents.

2.3. General Procedures. As shown in Figure 2, flow lines were inserted into luminol, carrier (doubly deionized water), UA, and $\mathrm{Co}^{2+}$ solutions, respectively. The pump was started with the stream of doubly deionized water at a constant flow rate of $2.0 \mathrm{~mL} \mathrm{~min}^{-1}$ to wash the whole system. Then $100 \mu \mathrm{L}$ of luminol solution was injected into the flow system by the six-way valve and, thereafter, merged with the premixed, homogeneous stream of UA and $\mathrm{Co}^{2+}$. The entire mixed solution was then delivered into the CL cell, producing CL emission. The CL signal was detected by PMT, and the PMT negative voltage was set as $700 \mathrm{~V}$. The CL intensity decrement $\left(\Delta I_{\mathrm{CL}}=I_{0}-I_{s}\right)$, where $I_{0}$ and $I_{s}$ were defined as CL intensity in the absence and presence of UA, respectively, was used as the quantitative parameter for UA concentration.

2.4. Sample Preparation. The urine samples, which came from volunteers who have prehydrated, were collected in beakers with volumes recorded. The UA concentrations in urine samples were measured directly after an appropriate dilution. When necessary, urine samples were refrigerated at $4^{\circ} \mathrm{C}$ and were determined as soon as possible to guarantee the sample integrity.

The human serum samples were obtained from the Hospital of Northwest University. After centrifugation, $0.1 \mathrm{~mL}$ supernatant was diluted with doubly deionized water and mixed thoroughly for CL determination after dilution.

\section{Results and Discussion}

3.1. Optimum Experimental Conditions for the Determination of UA. Two manifolds of quantitatively injecting luminol or UA sample into the carrier stream by six-way valve were investigated. It was found that two significantly different results were obtained. Using the manifold of quantitatively injecting luminol by six-way valve, a whole analytical process including sampling and washing could be accomplished within $36 \mathrm{~s}$, offering a ST of $100 \mathrm{~h}^{-1}$ accordingly. Whereas by using the manifold of injecting UA, the same analytical process needed $120 \mathrm{~s}$, yielding the ST of $30 \mathrm{~h}^{-1}$. It was clear that the ST of the manifold of injecting luminol shown in Figure 2 is about 3 -fold to that of injecting UA. Therefore, the manifold depicted in Figure 2 was chosen in subsequent work.

The effect of luminol concentration $\left(5.0 \times 10^{-7} \sim 5.0 \times\right.$ $\left.10^{-5} \mathrm{~mol} \mathrm{~L}^{-1}\right)$ and $\mathrm{Co}^{2+}$ concentration $\left(7.0 \times 10^{-10} \sim\right.$ $\left.7.0 \times 10^{-8} \mathrm{~mol} \mathrm{~L}^{-1}\right)$ on the $\mathrm{CL}$ intensity was investigated, respectively. As shown in Figure 3(a), it can be seen that the CL signal increased steadily with increasing concentration of luminol up to $5.0 \times 10^{-6} \mathrm{~mol} \mathrm{~L}^{-1}$, above which the CL signal tended to be stable. Thus, $5.0 \times 10^{-6} \mathrm{~mol} \mathrm{~L}^{-1}$ luminol was chosen as the optimal. It is also clear in Figure 3(b) that the CL intensity rose drastically when the $\mathrm{Co}^{2+}$ concentration increased to $1.0 \times 10^{-8} \mathrm{~mol} \mathrm{~L}^{-1}$ and then increased slowly from a higher concentration. Therefore, $1.0 \times 10^{-8} \mathrm{~mol} \mathrm{~L}^{-1}$ was chosen as the optimum concentration of $\mathrm{Co}^{2+}$. Owing to the nature of luminol CL reaction, which was favorable in alkaline medium, $\mathrm{NaOH}$ was added into luminol solution to increase the sensitivity of this CL system. A series of $\mathrm{NaOH}$ solutions ranging from $1.0 \times 10^{-4}$ to $1.0 \times 10^{-1} \mathrm{~mol} \mathrm{~L}^{-1}$ was tested. At $2.5 \times 10^{-2} \mathrm{~mol} \mathrm{~L}^{-1} \mathrm{NaOH}$, the CL signal could reach 


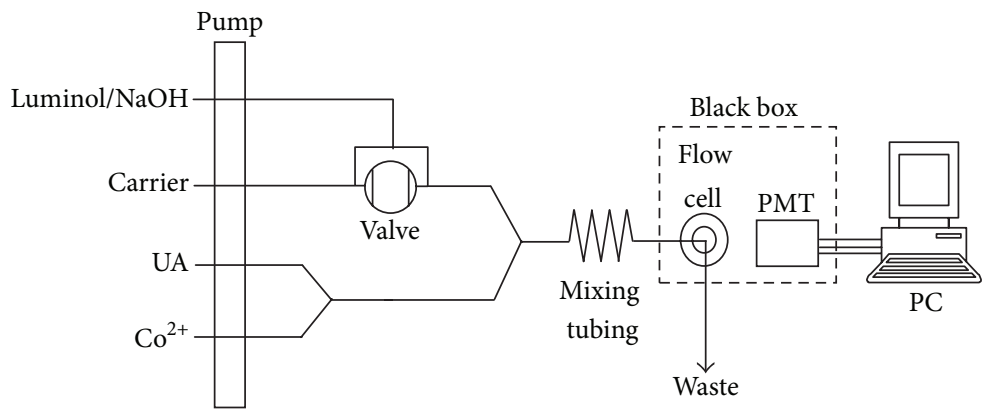

FIGURE 2: Schematic diagram for the determination of UA.

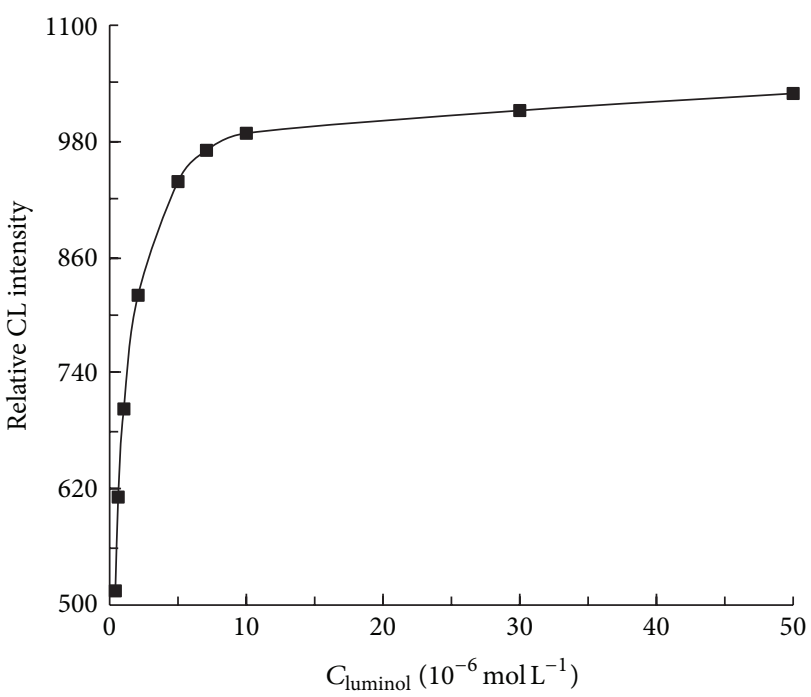

(a)

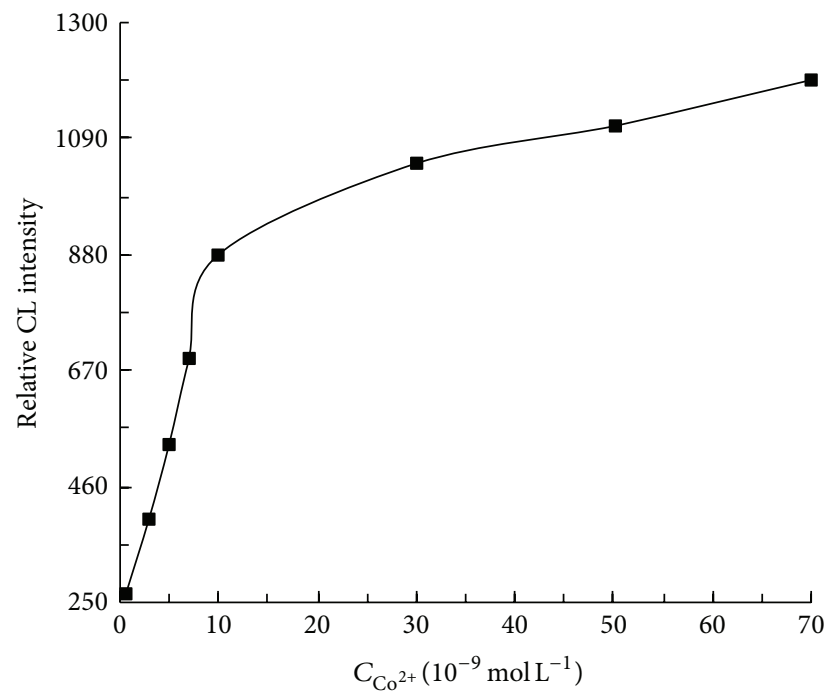

(b)

Figure 3: Effect of luminol (a) and $\mathrm{Co}^{2+}$ (b) concentrations on the CL intensity. (a) The concentration of $\mathrm{Co}^{2+}$ was $1.0 \times 10^{-8}$ mol L ${ }^{-1}$; (b) the concentration of luminol was $5.0 \times 10^{-6} \mathrm{~mol} \mathrm{~L}^{-1}$.

a maximum value. Hence, $2.5 \times 10^{-2} \mathrm{~mol} \mathrm{~L}^{-1}$ of $\mathrm{NaOH}$ was the optimal concentration for this CL system.

The flow rate and mixing tube length had a great effect on the CL intensity. A lower flow rate would slow down the sampling rate and cause dilution effect. Although higher flow rate can increase signal to noise $(\mathrm{S} / \mathrm{N})$, the precision of this method decreased. Considering a good sensitivity, a better precision, and a lower reagent consumption, a flow rate of $2.0 \mathrm{~mL} \mathrm{~min}{ }^{-1}$ was selected for this CL system. The effect of mixing tubing on CL intensity was also tested with the mixing tube lengths ranging from 5.0 to $20.0 \mathrm{~cm}$. It was found that a $10.0 \mathrm{~cm}$ of mixing tube afforded the best results with good sensitivity and reproducibility. Accordingly, this length was chosen in the subsequent experiments.

3.2. The Relative CL Intensity-Time Profile. The relative CL intensity-time profiles of different reactions were given in Figure 4 . It can be seen that the time $\left(T_{\max }\right)$ for reaching maximum CL intensity $\left(I_{\max }\right)$ of luminol- $\mathrm{Co}^{2+}$ reaction (curve 1) and luminol-dissolved oxygen reaction (curve 5) were 4.0 and $4.4 \mathrm{~s}$ with the $I_{\max }$ of 939 and 59, respectively; the $T_{\max }$ for luminol- $\mathrm{Co}^{2+}$ reaction in the presence of UA (curves 2-4) was $4.0 \mathrm{~s}$, while the $I_{\max }$ decreased from 939 to 750 (by 20.1\%), 550 (by 41.4\%), and 310 (by 66.9\%) at 5.0 , 30.0 , and $300.0 \mathrm{nmol} \mathrm{L}^{-1} \mathrm{UA}$, correspondingly. These experiments were carried out by the optimized concentrations of luminol and $\mathrm{Co}^{2+}$, which were $5.0 \times 10^{-6} \mathrm{~mol} \mathrm{~L}^{-1}$ and $1.0 \times$ $10^{-8} \mathrm{~mol} \mathrm{~L}^{-1}$.

3.3. Operational Stability of the FI-CL System. $100 \mu \mathrm{L}$ of luminol solution $\left(5.0 \times 10^{-6} \mathrm{~mol} \mathrm{~L}^{-1}\right)$ was injected into the carrier stream and thereafter merged with the premixing stream of $\mathrm{Co}^{2+}\left(1.0 \times 10^{-8} \mathrm{~mol} \mathrm{~L}^{-1}\right)$ and UA $\left(10.0\right.$ and $100.0 \mathrm{nmol} \mathrm{L}^{-1}$, resp.). The relative $\mathrm{CL}$ intensity was recorded to test the stability and reproducibility of the luminol- $\mathrm{Co}^{2+}$ system. The FI system was regularly used over $8 \mathrm{~h}$ per day and the experiment lasted for 5 days. The results were listed in Table 1. Each result was the average of five separate determinations, and the RSDs were less than 3.5\%. It suggested that the system exerted good stability. 


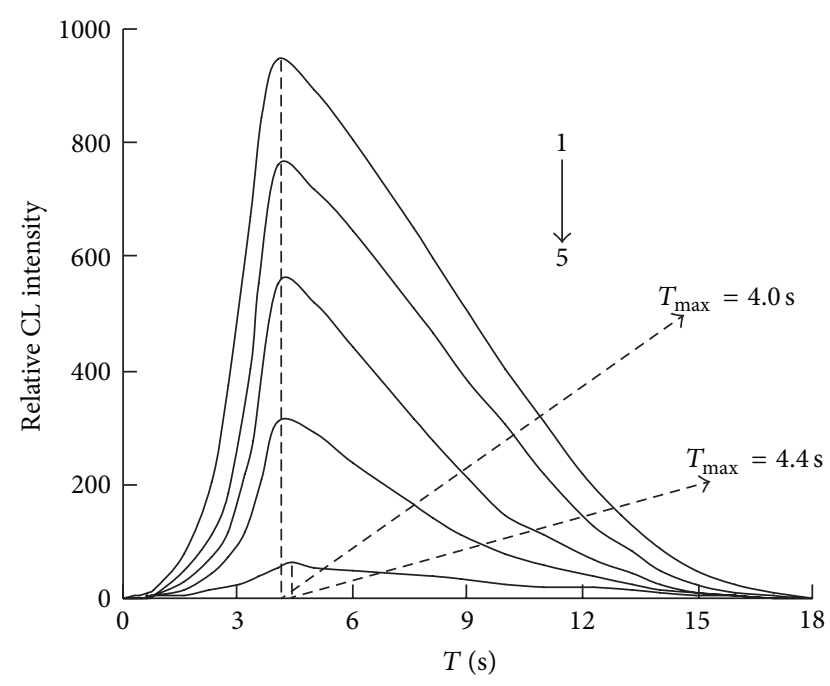

FIgURE 4: The relative CL intensity-time profile. Curve 1: luminol$\mathrm{Co}^{2+}$ system; Curve 2-4: luminol-Co ${ }^{2+}-\mathrm{UA}$ system; Curve 5: luminol-dissolved oxygen system; Luminol: $5.0 \times 10^{-6} \mathrm{~mol} \mathrm{~L}^{-1}$; $\mathrm{Co}^{2+}: 1.0 \times 10^{-8} \mathrm{~mol} \mathrm{~L}^{-1}$; UA: $5.0,30.0$ and $300.0 \mathrm{nmol} \mathrm{L}^{-1}$ for Curves 2,3 , and 4 , respectively.

3.4. Analytical Performance of UA Measurement. Under the optimal experimental conditions, a series of UA standard solutions was determined. It was found that the CL intensity of luminol- $\mathrm{Co}^{2+}$ system was obviously inhibited, and the decrements of CL intensity were linear with the logarithm of UA concentrations in the range of $3.0-500.0 \mathrm{nmol} \mathrm{L}^{-1}$, giving the calibration equation of $\Delta I_{\mathrm{CL}}=106.8 \ln C_{\mathrm{UA}}+33.1(R=$ $0.9982)$ with the LOD of $1.0 \mathrm{nmol} \mathrm{L}^{-1}(3 \sigma)$. The RSDs $(n=5)$ at $5.0,50.0$, and $300.0 \mathrm{nmol} \mathrm{L}^{-1} \mathrm{UA}$ were $2.9 \%, 2.3 \%$, and $1.9 \%$, respectively. At a flow rate of $2.0 \mathrm{~mL} \mathrm{~min}^{-1}$, a complete analytical process including sampling and washing could be accomplished within $36 \mathrm{~s}$, offering a ST of $100 \mathrm{~h}^{-1}$.

3.5. Interference Studies. To test for the interference of foreign substances on UA quantification, a potential interfering analyte was added in increasing amounts to the UA standard solution, and the relative CL intensity was examined with a relative error controlled at 5\% level. The tolerable concentration ratios of foreign substances with respect to $10 \mathrm{ng} \mathrm{mL}^{-1}$ $\mathrm{UA}$ were over $4.0 \times 10^{4}$ for $\mathrm{SO}_{4}{ }^{2-}, \mathrm{NO}_{3}{ }^{-}, \mathrm{CO}^{2-}$, oxalate, $\mathrm{PO}_{4}{ }^{3-}$, glucose, and ethanol; $1.0 \times 10^{4}$ for $\mathrm{Ba}^{2+}, \mathrm{Zn}^{2+}$ and $\mathrm{HCO}_{3}{ }^{-} ; 9.0 \times 10^{3}$ for urea; $5.0 \times 10^{3}$ for $\mathrm{Mg}^{2+}$ and $\mathrm{Ca}^{2+}$; $5.0 \times 10^{2}$ for $\mathrm{Ni}^{2+}$ and $\mathrm{Cr}^{3+} ; 4.0 \times 10^{2}$ for $\mathrm{Cu}^{2+}, \mathrm{Mn}^{2+}$, and ascorbic acid; $1.0 \times 10^{2}$ for creatine and $\mathrm{Fe}^{3+} / \mathrm{Fe}^{2+} ; 20$ for vitamin $\mathrm{B}_{12}$, respectively. Compounds abundant in human serum and urine such as lipids, proteins, and salts had no obvious interference for the determination of UA.

3.6. Possible Quenching Mechanism of UA on Luminol-Co ${ }^{2+}$ CL Reaction. From Figure 4, it was clear that the $I_{\max }$ of luminol-dissolved oxygen reaction in the presence of $\mathrm{Co}^{2+}$ increased from 59 to 939 and the $T_{\max }$ changed from 4.4

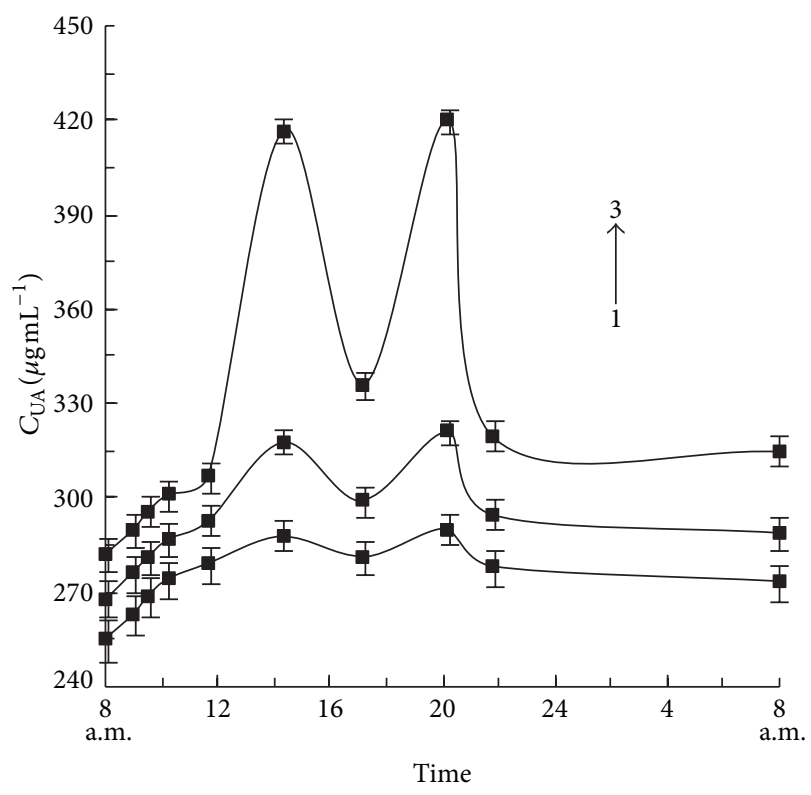

FIGURE 5: Metabolism of UA in human urine with different food during 24 h. Curve 1: porridge; Curve 2: vegetables; Curve 3: meats.

to $4.0 \mathrm{~s}$; it also can be seen that the $I_{\max }$ of luminol$\mathrm{Co}^{2+}$ system in the presence of UA decreased obviously at increasing UA concentration with the identical $T_{\max }$ of $4.0 \mathrm{~s}$. The CL intensities generated by online ultrasonically degassed solutions and general solutions were compared, and results showed that the CL intensity from the degassed solutions decreased obviously with regard to the CL intensity from general solutions, suggesting the oxygen dissolved in solution with solubility of $0.26 \mathrm{mM}$ [40] was involved in the CL reaction. Furthermore, it is known that $\mathrm{Co}^{2+}$ can catalyze luminol-dissolved oxygen $\mathrm{CL}$ reaction, with $\mathrm{O}_{2}{ }^{-}$ being increased which led to the CL intensity from luminol being remarkably enhanced [41]. While in the presence of $\mathrm{UA}, \mathrm{O}_{2}{ }^{-}$would react with $\mathrm{UA}$ and oxidize $\mathrm{UA}$ to allantoin [42]. Thus the quenching mechanism of UA on luminol- $\mathrm{Co}^{2+}$ $\mathrm{CL}$ reaction can be explained as the decreased amount of $\mathrm{O}_{2}{ }^{-}$, which was consumed by UA oxidation reaction, causing the $\mathrm{CL}$ intensity of luminol- $\mathrm{Co}^{2+}$ system to be inhibited.

\section{Applications}

4.1. Real-Time Monitoring of UA Excretion in Human $24 \mathrm{~h}$ Urine. Three volunteers refrained from vegetables and meats intake for 1 day prior to the experiment. In the following 3 consecutive days, volunteers ingested diets at 12:30 am and 6:30 pm daily, with porridge, vegetables, and meats, respectively. On the 3 rd day, the urine samples were periodically collected from volunteers and detected by the proposed CL method, with results being summarized in Table 2. It can be seen that the total UA excreted in $24 \mathrm{~h}$ urine from the three volunteers were $741.6,797.7$, and $878.4 \mathrm{mg}$, respectively, which indicated that the UA excretions were related to food intake with highest UA for meat intake and lowest UA for porridge intake. The details of UA metabolism in urine during $24 \mathrm{~h}$ 
TABLE 1: Stability and reproducibility test of the FI-CL system for UA determination ${ }^{\mathrm{a}}$.

\begin{tabular}{|c|c|c|c|c|c|c|}
\hline Time (day) & $I_{0}$ (blank) & RSD (\%) & $I_{s} 10.0\left(\mathrm{nmol} \mathrm{L}^{-1}\right)$ & RSD (\%) & $I_{s}\left(100.0 \mathrm{nmol} \mathrm{L}^{-1}\right)$ & RSD (\%) \\
\hline 1st & 943 & 2.8 & 658 & 2.6 & 421 & 2.2 \\
\hline 2nd & 941 & 2.9 & 660 & 2.5 & 417 & 2.4 \\
\hline $3 \mathrm{rd}$ & 938 & 3.1 & 656 & 2.7 & 415 & 2.5 \\
\hline 4 th & 945 & 2.7 & 662 & 2.5 & 420 & 2.3 \\
\hline 5 th & 934 & 3.2 & 654 & 2.8 & 414 & 2.6 \\
\hline
\end{tabular}

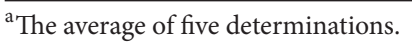

TABLE 2: Determination of $24 \mathrm{~h}$ urine UA excretion ${ }^{\mathrm{a}}$.

\begin{tabular}{lccr}
\hline Volunteers no. & Diets & $m^{\mathrm{b}} / v^{\mathrm{c}}(\mathrm{mg} / \mathrm{mL})$ & $C_{\mathrm{UA}}{ }^{\mathrm{d}}\left(\mu \mathrm{g} \mathrm{mL}{ }^{-1}\right)$ \\
\hline 1 & Porridge & $741.6 \pm 20.0 / 2700$ & $274.7 \pm 7.4$ \\
2 & Vegetables & $797.7 \pm 25.6 / 2730$ & $292.2 \pm 9.4$ \\
3 & Meats & $878.4 \pm 27.2 / 2670$ & $329.0 \pm 10.2$ \\
\hline
\end{tabular}

${ }^{\mathrm{a}}$ The average of five determinations; ${ }^{\mathrm{b}}$ the content of UA in urine sample; ${ }^{c}$ the volume of urine; ${ }^{\mathrm{d}}$ the concentration of UA, calculated by b/c.

TABLE 3: Determination for UA in human serum samples ${ }^{\mathrm{a}}$.

\begin{tabular}{|c|c|c|c|c|c|}
\hline & Samples no. & $\begin{array}{l}\text { Added/Found } \\
\left(\mathrm{ng} \mathrm{mL} \mathrm{mL}^{-1}\right)\end{array}$ & RSD (\%) & Recovery (\%) & $\begin{array}{c}C_{\mathrm{UA}}{ }^{\mathrm{b}} \\
\left(\mu \mathrm{g} \mathrm{mL}^{-1}\right)\end{array}$ \\
\hline \multirow{6}{*}{ Volunteer 1} & \multirow{2}{*}{1} & $0 / 7.6$ & 3.3 & \multirow{2}{*}{96.6} & \multirow{2}{*}{$38.0 \pm 1.5$} \\
\hline & & $5.0 / 12.4$ & 2.4 & & \\
\hline & \multirow{2}{*}{2} & $0 / 8.1$ & 3.0 & \multirow{2}{*}{103.1} & \multirow{2}{*}{$40.2 \pm 1.2$} \\
\hline & & $10.0 / 18.4$ & 1.7 & & \\
\hline & \multirow{2}{*}{3} & $0 / 7.9$ & 3.1 & \multirow{2}{*}{97.8} & \multirow{2}{*}{$39.5 \pm 1.4$} \\
\hline & & $7.0 / 14.7$ & 2.1 & & \\
\hline \multirow{6}{*}{ Volunteer 2} & \multirow{2}{*}{4} & $0 / 9.8$ & 2.8 & \multirow{2}{*}{104.3} & \multirow{2}{*}{$49.1 \pm 0.8$} \\
\hline & & $5.0 / 15.0$ & 2.0 & & \\
\hline & \multirow{2}{*}{5} & 0/10.1 & 2.7 & \multirow{2}{*}{105.7} & \multirow{2}{*}{$50.5 \pm 0.7$} \\
\hline & & 7.0/17.5 & 1.9 & & \\
\hline & \multirow{2}{*}{6} & $0 / 10.3$ & 2.6 & \multirow{2}{*}{106.4} & \multirow{2}{*}{$51.4 \pm 0.6$} \\
\hline & & $10.0 / 20.9$ & 1.6 & & \\
\hline
\end{tabular}

${ }^{\mathrm{a}}$ The average of five determinations; ${ }^{\mathrm{b}}$ the average concentration of UA $(n=5)$.

TABLE 4: Comparison of different methods for UA determination.

\begin{tabular}{|c|c|c|c|c|}
\hline Methods & 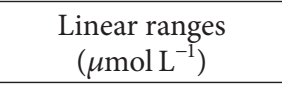 & $\begin{array}{c}\text { LODs } \\
\left(\mu \mathrm{mol} \mathrm{L}^{-1}\right)\end{array}$ & Samples & References \\
\hline $\mathrm{CE}$ & $10 \sim 5.0 \times 10^{2}$ & 3.3 & Human urine and serum & [7] \\
\hline EA & $10 \sim 1.6 \times 10^{2}$ & 2.6 & Human serum & {$[8]$} \\
\hline \multirow{2}{*}{ HPLC } & $5 \sim 1.0 \times 10^{3}$ & 1.5 & Human serum & {$[9]$} \\
\hline & $10 \sim 5.0 \times 10^{2}$ & $4.3 \times 10^{-1}$ & Human serum & {$[10]$} \\
\hline \multirow{2}{*}{ DPV } & $1 \sim 1.6 \times 10^{2}$ & $1.9 \times 10^{-1}$ & Human urine and serum & {$[11]$} \\
\hline & $3.0 \times 10^{-1} \sim 1.0 \times 10^{2}$ & $3.0 \times 10^{-1}$ & Human urine & {$[12]$} \\
\hline \multirow{2}{*}{ UV-Vis } & $1 \sim 1.0 \times 10^{2}$ & $3.0 \times 10^{-1}$ & Human urine & {$[13]$} \\
\hline & $10 \sim 1.0 \times 10^{2}$ & 3.0 & Human urine & {$[14]$} \\
\hline \multirow[t]{2}{*}{ CL } & $1.0 \times 10^{-4} \sim 7$ & $1.1 \times 10^{-5}$ & Human urine and serum & [32] \\
\hline & $4.8 \sim 1.7 \times 10^{2}$ & 2.9 & Human urine and serum & {$[15]$} \\
\hline \multirow{3}{*}{ FI-CL } & $4.0 \times 10^{-1} \sim 2.0 \times 10^{2}$ & $1.2 \times 10^{-1}$ & Human serum & {$[16]$} \\
\hline & $3.0 \times 10^{-2} \sim 3$ & $1.0 \times 10^{-2}$ & Human urine and serum & {$[17]$} \\
\hline & $3.0 \times 10^{-3} \sim 5.0 \times 10^{-1}$ & $1.0 \times 10^{-3}$ & Human urine and serum & This study \\
\hline
\end{tabular}


were given in Figure 5, showing that the concentrations of UA simultaneously reached the maximum at $2 \mathrm{~h}$ after meals with the values of 288,318 , and $417 \mu \mathrm{g} \mathrm{mL}^{-1}$, corresponding to porridge, vegetables, and meats intake, respectively.

4.2. Determination of UA in Human Serum Samples. The proposed method was also applied to determining UA in samples of human serum. The serum samples were collected from two volunteers, with no. 1-3 from volunteer 1 and no. 4-6 from volunteer 2. It was found that the serum UA concentrations were $38.0 \pm 1.5-51.4 \pm 0.6 \mu \mathrm{g} \mathrm{mL}^{-1}$, which were in the normal range of $22-77 \mu \mathrm{g} \mathrm{mL}^{-1}$ [43]. To validate the proposed method for UA determination, recovery studies were carried out on samples to which known amounts of UA (5.0, 7.0, and $10.0 \mathrm{ng} \mathrm{mL}^{-1}$ ) were added. The results were listed in Table 3 with recoveries varied from $96.6 \%$ to $106.4 \%$ and RSDs less than $3.5 \%$, which confirmed that this presented FICL method was capable of UA quantification.

\section{Conclusion}

A rapid and cost-effective FI-CL method with luminol- $\mathrm{Co}^{2+}$ system for quantitative monitoring of urine UA excretion in $24 \mathrm{~h}$ at nanomolar level was described for the first time. In comparison with other reported methods for determining UA (Table 4), this proposed FI-CL analysis was attractive in relatively high sensitivity and wide linear range. Despite the fact that the sensitivity was a little inferior to the previous static CL for UA determination [32], the current FI-CL approach provided an amazing ST of $100 \mathrm{~h}^{-1}$, confirming the promise of this method for quantitative monitoring and realtime UA analysis.

\section{Conflicts of Interests}

There is no conflict of interests for this original unpublished work which has not been submitted to anywhere.

\section{Acknowledgments}

The authors gratefully acknowledge the financial support from the National Nature Science Foundation of China (no. 21275118) and the Open Funds from the Key Laboratory of Synthetic and Natural Functional Molecule Chemistry of Ministry of Education, China.

\section{References}

[1] M. S. Lipkowitz, "Regulation of uric acid rxcretion by the kidney," Current Rheumatology Reports, vol. 14, no. 2, pp. 179188, 2012.

[2] K. L. Rock, H. Kataoka, and J. J. Lai, "Uric acid as a danger signal in gout and its comorbidities," Nature Reviews Rheumatology, vol. 9, pp. 13-23, 2013.

[3] V. Lapsia, R. J. Johnson, B. Dass et al., "Elevated uric acid increases the risk for acute kidney injury," The American Journal of Medicine, vol. 125, no. 3, pp. 302.e9-302.e17, 2012.
[4] T. Yang, C. H. Chu, C. H. Bai et al., "Uric acid level as a risk marker for metabolic syndrome: a Chinese cohort study," Atherosclerosis, vol. 220, no. 2, pp. 525-531, 2012.

[5] S. Kivity, E. Kopel, E. Maor et al., "Association of serum uric acid and cardiovascular disease in healthy adults," The American Journal of Cardiology, vol. 111, no. 8, pp. 1146-1151, 2013.

[6] I. Sluijs, J. W. J. Beulens, D. L. van der A, A. M. W. Spijkerman, M. B. Schulze, and Y. T. van der Schouw, "Plasma uric acid is associated with increased risk of Type 2 diabetes independent of diet and metabolic risk factors," The Journal of Nutrition, vol. 143, no. 1, pp. 80-85, 2013.

[7] W. Pormsila, S. Krähenbühl, and P. C. Hauser, "Capillary electrophoresis with contactless conductivity detection for uric acid determination in biological fluids," Analytica Chimica Acta, vol. 636, no. 2, pp. 224-228, 2009.

[8] B. Thakur and S. N. Sawant, "Polyaniline/prussian-bluebased amperometric biosensor for detection of uric acid," ChemPlusChem, vol. 78, no. 2, pp. 166-174, 2013.

[9] R. Kand'ár, P. Drábková, and R. Hampl, “The determination of ascorbic acid and uric acid in human seminal plasma using an HPLC with UV detection," Journal of Chromatography B, vol. 879, no. 26, pp. 2834-2839, 2011.

[10] R. Ferin, M. L. Pavão, and J. Baptista, "Rapid, sensitive and simultaneous determination of ascorbic and uric acids in human plasma by ion-exclusion HPLC-UV," Clinical Biochemistry, vol. 46, no. 7-8, pp. 665-669, 2013.

[11] E. Alipour, M. R. Majidi, A. Saadatirad, and S. M. Golabi, "Determination of uric acid in biological samples on the pretreated pencil graphite electrode," Analytical Methods, vol. 4, no. 8, pp. 2288-2295, 2012.

[12] M. I. Khan, A. M. J. Haque, and K. Kim, "Electrochemical determination of uric acid in the presence of ascorbic acid on electrochemically reduced graphene oxide modified electrode," Journal of Electroanalytical Chemistry, vol. 700, pp. 54-59, 2013.

[13] A. Waseem, M. Yaqoob, A. Nabi, G. Murtaza, and I. Hussain, "Flow-injection spectrophotometric determination of uric acid in urine via Prussian blue reaction," Chemical Research in Chinese Universities, vol. 27, no. 6, pp. 929-933, 2011.

[14] D. L. Rocha and F. R. P. Rocha, "A flow-based procedure with solenoid micro-pumps for the spectrophotometric determination of uric acid in urine," Microchemical Journal, vol. 94, no. 1, pp. 53-59, 2010.

[15] D. Y. He, Z. J. Zhang, Y. Huang, Y. F. Hu, H. J. Zhou, and D. L. Chen, "Chemiluminescence microflow injection analysis system on a chip for the determination of uric acid without enzyme," Luminescence, vol. 20, no. 4-5, pp. 271-275, 2005.

[16] C. Y. Yang and Z. J. Zhang, "A novel flow-injection chemiluminescence determination of uric acid based on diperiodatoargentate(III) oxidation," Talanta, vol. 81, no. 1-2, pp. 477-481, 2010.

[17] Z. H. Song and S. Hou, "Chemiluminescence assay for uric acid in human serum and urine using flow-injection with immobilized reagents technology," Journal of Analytical Chemistry, vol. 372, no. 2, pp. 327-332, 2002.

[18] J. C. Yuan and A. M. Shiller, "Determination of subnanomolar levels of hydrogen peroxide in seawater by reagent-injection chemiluminescence detection," Analytical Chemistry, vol. 71, no. 10, pp. 1975-1980, 1999.

[19] K. E. Haapakka, "The mechanism of the cobalt(II)-catalyzed electro-generated chemiluminescence of luminol in aqueous alkaline solution," Analytica Chimica Acta, vol. 141, pp. 263-275, 1982. 
[20] T. G. Burdo and W. R. Seitz, "Mechanism of cobalt catalysis of luminol chemiluminescence," Analytical Chemistry, vol. 47, no. 9, pp. 1639-1643, 1975.

[21] F. J. Pérez and S. Rubio, "An improved chemiluminescence method for hydrogen peroxide determination in plant tissues," Plant Growth Regulation, vol. 48, no. 1, pp. 89-95, 2006.

[22] J. A. M. Pulgarín, L. F. G. Bermejo, and A. C. Durán, "Fast simultaneous determination of traces of $\mathrm{Cu}(\mathrm{II})$ and $\mathrm{Co}(\mathrm{II})$ in soils and sediments with the luminol/perborate chemiluminescent system," Environmental Monitoring and Assessment, vol. 185, no. 1, pp. 573-580, 2013.

[23] A. Tahirović, A. Čopra, E. Omanović-Mikličanin, and K. Kalcher, "A chemiluminescence sensor for the determination of hydrogen peroxide," Talanta, vol. 72, no. 4, pp. 1378-1385, 2007.

[24] L. Marle and G. M. Greenway, "Determination of hydrogen peroxide in rainwater in a miniaturised analytical system," Analytica Chimica Acta, vol. 548, no. 1-2, pp. 20-25, 2005.

[25] H. C. Yeh, W. T. Hsu, and W. Y. Lin, "Enhancement in chemiluminescence by carbonate for cobalt(ll)-catalyzed oxidation of luminol with hydrogen peroxide," Journal of the Chinese Chemical Society, vol. 52, no. 4, pp. 657-664, 2005.

[26] J. C. Ren and X. Y. Huang, "Sensitive and universal indirect chemiluminescence detection for capillary electrophoresis of cations using cobalt(II) as a probe ion," Analytical Chemistry, vol. 73, no. 11, pp. 2663-2668, 2001.

[27] A. Waseem, M. Yaqoob, A. Nabi, and M. A. Siddiqui, "Determination of carbaryl by flow injection with luminol chemiluminescence inhibition detection," International Journal of Environmental Analytical Chemistry, vol. 87, no. 12, pp. 825-832, 2007.

[28] Z. H. Song, S. Hou, X. Y. Yu, X. F. Xie, and X. D. Shao, "In vitro monitoring of picogram levels of captopril in human urine using flow injection chemiluminescence with immobilized reagent technique," Analytical Letters, vol. 39, no. 6, pp. 11151127, 2006.

[29] J. A. Murillo Pulgarín, L. F. García Bermejo, and M. Nieves Sánchez García, "Flow injection chemiluminescence determination of vitamin $B_{12}$ using on-line UV-persulfate photooxidation and charge coupled device detection," Luminescence, vol. 26, no. 6, pp. 536-542, 2011.

[30] Y. J. Dong and Z. L. Wang, "Determined GA by FI-CE in liminol- $\mathrm{H}_{2} \mathrm{O}_{2}$ system," Journal of the Chinese Chemical Society, vol. 60, no. 1, pp. 108-112, 2013.

[31] D. L. Giokas, A. G. Vlessidis, and N. P. Evmiridis, "On-line selective detection of antioxidants free-radical scavenging activity based on Co(II)/EDTA-induced luminol chemiluminescence by flow injection analysis," Analytica Chimica Acta, vol. 589, no. 1, pp. 59-65, 2007.

[32] E.-B. Liu and H. Q. Wei, "Determination of uric acid by chemiluminescence," Spectroscopy and Spectral Analysis, vol. 25, no. 8, pp. 1213-1215, 2005.

[33] F. G. Lu, M. Sun, L. L. Fan et al., "Flow injection chemiluminescence sensor based on core-shell magnetic molecularly imprinted nanoparticles for determination of chrysoidine in food samples," Sensors and Actuators B, vol. 173, pp. 591-598, 2012.

[34] H. J. Zeng, R. Yang, Q. W. Wang, J. J. Li, and L. B. Qu, "Determination of melamine by flow injection analysis based on chemiluminescence system," Food Chemistry, vol. 127, no. 2, pp. 842-846, 2011.

[35] L. C. Niu, Z. H. Song, and D. H. Chen, "Determination of Sudan IV in hot chilli powder with luminol/dissolved oxygen chemiluminescence system," Journal of the Science of Food and Agriculture, vol. 90, no. 2, pp. 338-342, 2010.

[36] W. W. Liu, W. Cao, W. H. Liu, K. Du, and P. X. Gong, "Determination of phenol by flow-injection with chemiluminescence detection based on the hemin-catalysed luminolhydrogen peroxide reaction," Spectrochimica Acta A, vol. 85, no. 1, pp. 283-287, 2012.

[37] D. Christodouleas, C. Fotakis, A. Economou, K. Papadopoulos, M. Timotheou-Potamia, and A. Calokerinos, "Flow-based methods with chemiluminescence detection for food and environmental analysis: a review," Analytical Letters, vol. 44, no. 1-3, pp. 176-215, 2011.

[38] C. Gómez-Benito, S. Meseguer-Lloret, and S. Torres-Cartas, "Sensitive determination of Fenamiphos in water samples by flow injection photoinduced chemiluminescence," International Journal of Environmental Analytical Chemistry, vol. 93, no. 2, pp. 152-165, 2013.

[39] J. Ballesta-Claver, I. F. Díaz Ortega, M. C. Valencia-Mirón, and L. F. Capitán-Vallvey, "Disposable luminol copolymer-based biosensor for uric acid in urine," Analytica Chimica Acta, vol. 702, no. 2, pp. 254-261, 2011

[40] L. L. Klopf and T. A. Nieman, "Effect of iron(II), cobalt(II), copper(II), and manganese(II) on the chemiluminescence of luminol in the absence of hydrogen peroxide," Analytical Chemistry, vol. 55, no. 7, pp. 1080-1083, 1983.

[41] Z. H. Song and S. Hou, "Sub-picogram determination of Vitamin $\mathrm{B}_{12}$ in pharmaceuticals and human serum using flow injection with chemiluminescence detection," Analytica Chimica Acta, vol. 488, no. 1, pp. 71-79, 2003.

[42] Y. Y. Sautin, W. Imaram, K. M. Kim, A. Angerhofer, G. Henderson, and R. Johnson, "Uric acid and oxidative stress," in Studies on Renal Disorders, pp. 143-159, Humana Press, New Jersey, NJ, USA, 2011.

[43] T. Ahuja, D. Kumar, V. K. Tanwar, V. Sharma, N. Singh, and A. M. Biradar, "An amperometric uric acid biosensor based on Bis[sulfosuccinimidyl] suberate crosslinker/3aminopropyltriethoxysilane surface modified ITO glass electrode," Thin Solid Films, vol. 519, no. 3, pp. 1128-1134, 2010. 

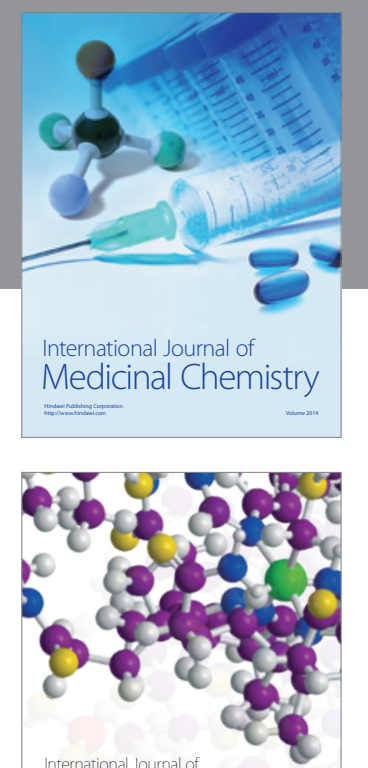

\section{Carbohydrate} Chemistry

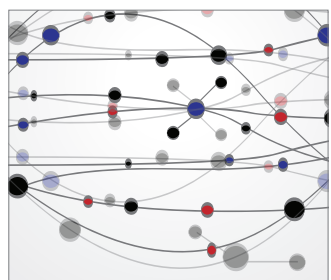

The Scientific World Journal
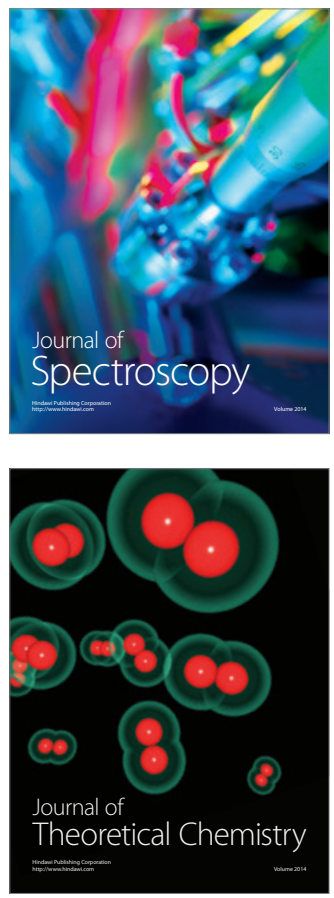
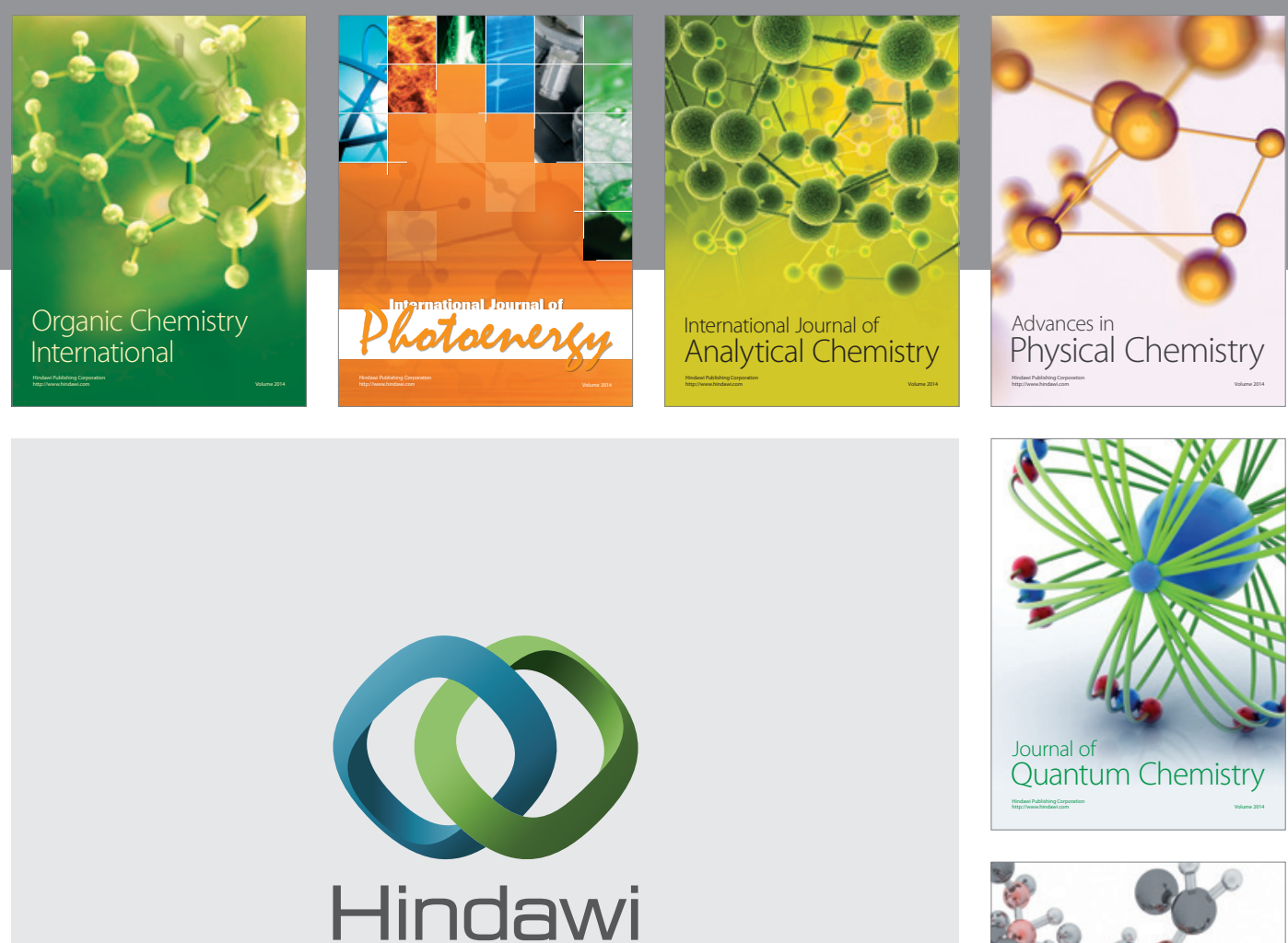

Submit your manuscripts at

http://www.hindawi.com

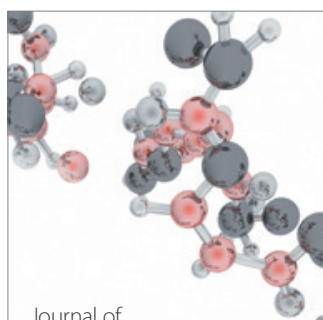

Analytical Methods

in Chemistry

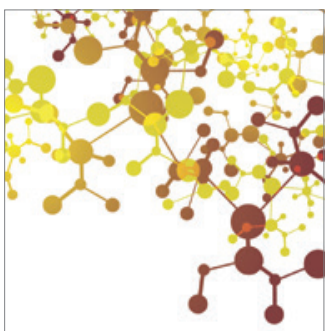

Journal of

Applied Chemistry

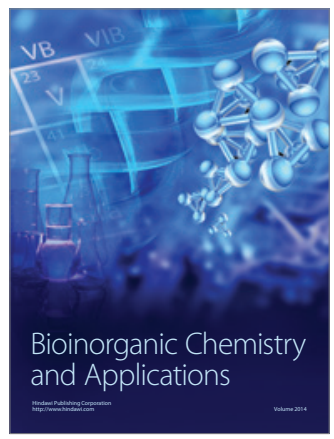

Inorganic Chemistry
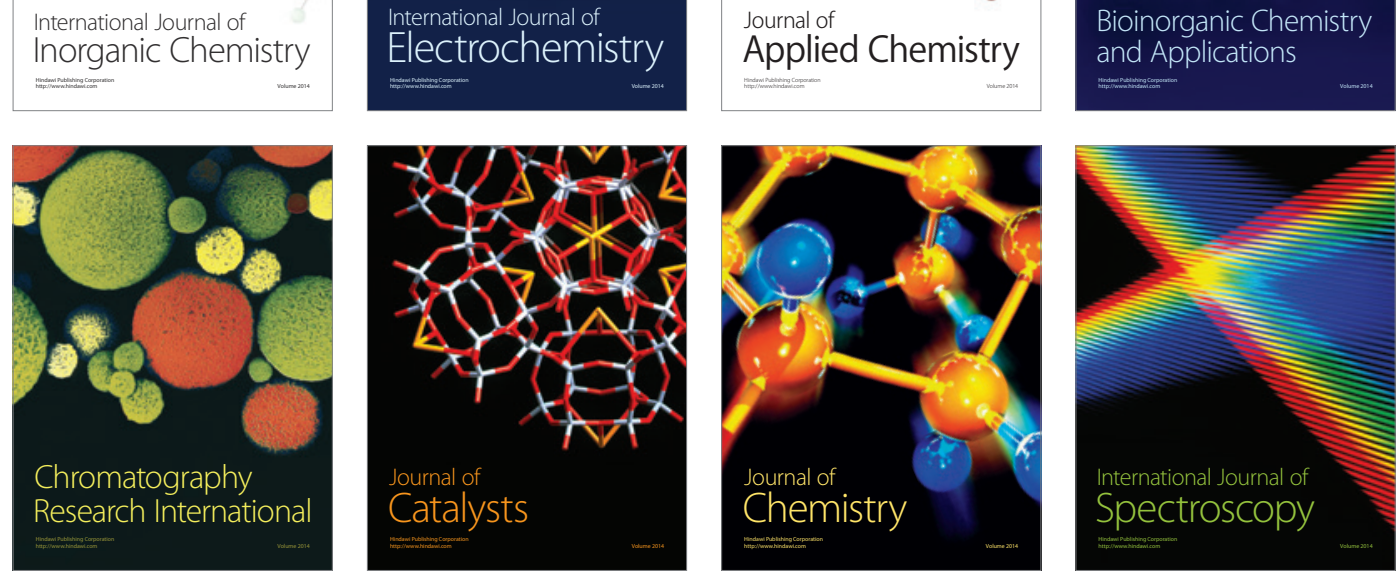